Supplement of Earth Surf. Dynam., 9, 771-793, 2021

https://doi.org/10.5194/esurf-9-771-2021-supplement

(C) Author(s) 2021. CC BY 4.0 License.

(c) (1)

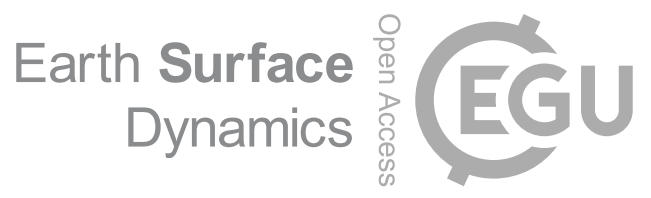

Supplement of

\title{
Stochastic alluvial fan and terrace formation triggered by a high-magnitude Holocene landslide in the Klados Gorge, Crete
}

Elena T. Bruni et al.

Correspondence to: Sean F. Gallen (sean.gallen@ colostate.edu) and Elena T. Bruni (elena.bruni@erdw.ethz.ch)

The copyright of individual parts of the supplement might differ from the article licence. 


\section{Supplement}

2 S1. Landslide runout modelling using DAN3D-Flex

3 Landslide runout has been modelled in recent years by multiple authors (Allen et al., 2009; Grämiger et al., 2016;

4 Hungr and Evans, 1996; Nagelisen et al., 2015; Preuth et al., 2010; Sosio et al., 2008; Xing et al., 2015) and

5 different software programs are available. One of them is Dynamic Analysis 3D (DAN3D) presented by

6 McDougall \& Hungr (2004). In DAN3D, a frictional model defines material behaviour using the meshless

7 Lagrangian numerical technique known as "smoothed particle hydrodynamics" (SPH). The modeller may choose

8 between frictional, plastic, Bingham, Newtonian, and Voellmy rheology. McDougall \& Hungr (2004) found that

9 landslide behaviour is best reconstructed when using frictional or Voellmy basal rheology, and several back-

10 analysed historical events exist where its application was successful (Allen et al., 2009; Grämiger et al., 2016;

11 Hungr and Evans, 1996; Nagelisen et al., 2015; Preuth et al., 2010; Sosio et al., 2008; Xing et al., 2015). Frictional

12 rheology is characterised by Eq. (1), where $\tau$ is the basal shear stress, $\sigma z$ the bed normal stress and $\varphi b$ is the bulk friction angle. The Voellmy rheology is defined by Eq. (2), where $\mu$ is the frictional coefficient (equivalent to $\left.\tan \tan \varphi_{b}\right), \rho$ is the material density in $\mathrm{kg} \mathrm{m}^{-3}, \mathrm{~g}$ the gravitational acceleration in $\mathrm{m} \mathrm{s}^{-2}, \mathrm{v}$ is the depth-averaged flow velocity in $\mathrm{m} \mathrm{s}^{-1}$, and $\xi$ is the turbulence coefficient in $\mathrm{m} \mathrm{s}^{-2}$. In short, adding to the basic frictional rheology equation, Voellmy rheology includes a "turbulent term" which is dependent on flow velocity and the density of the material and summarises the velocity-dependent factors of flow resistance (Hungr and Evans, 1996).

$\tau=\sigma_{z} \tan \tan \varphi_{b}$

$\tau=\sigma_{z} \mu+\frac{\rho g v^{2}}{\xi}$

The input parameters for both rheologies need to be defined through back-analysis. Constraints on the parameters may be deduced from the deposit's extent, the runout topography, and the material exposed along the sliding path. Additionally, previous studies provide first estimates of reasonable input parameters in similar environments. A common issue when modelling with DAN3D is that fluid pressure induces lateral spreading of a flow-like rock mass already in the source area (Aaron and Hungr, 2016b). However, it is more reasonable to assume the rock mass slides without much internal deformation in the rock avalanche's early stages. Therefore, a modified dynamic model was developed by Aaron et al. (2017), which allows for the simulation of an initial coherent phase of motion followed by the flow-like movement of a rock avalanche (DAN3D-Flex). The modified dynamic model results in a more accurate representation of rock slope failures (Aaron et al., 2017), and was used in this study.

DAN3D-Flex is the follow-up dynamic runout modelling program to DAN3D. It is used to model the runout of rapid mass movements across three-dimensional input topographies. The required input parameters are determined using back-analysis and include the internal friction of the material $(\varphi i)$ and the basal rheology (frictional and Voellmy) and their respective controlling parameters. If the frictional rheology is applied, a definition of basal friction $(\varphi b)$ and relative pore pressure (ru) is required. When applying the Voellmy model, the friction coefficient $\mu$ and the turbulence coefficient $\xi$ need to be defined. For rock avalanches, frictional or 
35 Voellmy rheology should be used (Aaron and Hungr, 2016b; Hungr, 1995). Many authors successfully applied 36 either one of these rheologies (Grämiger et al., 2016; Nagelisen et al., 2015), but Aaron and Hungr (2016a) argue 37 that while initial displacement is better simulated in frictional rheology, Voellmy rheology approximates the 38 runout in the deposition area better as it becomes more fluid-like. Runout modelling delivers information on the travel path, movement parameters, and deposit thickness and extent. 
41 We are confident that the runout modelling approximates a realistic landslide, mainly because the results are 42 consistent with our field observations. However, we here discuss three significant limitations to the model. Firstly, 43 the runout velocity reached a brief maximum of $\sim 200 \mathrm{~m} \mathrm{~s}^{-1}$ (Fig. S1), which is a staggeringly high value, 44 considering that published reports from historical and modern rock avalanches report maximum velocities of $\sim 50$ $45 \mathrm{~m} \mathrm{~s}^{-1}$ (Scheidegger, 1973; Sosio et al., 2008; USGS, 2016). Even though internal mechanisms such as rock 46 fragmentation may reduce frictional resistance on the sliding surface, thus increasing runout speed (Davies and 47 McSaveney, 2009; McSaveney and Davies, 2006), and the sand cloud resulting from the impact of the rock slab 48 with the valley floor will have travelled faster than the ground-based landslide, it remains unlikely that the initial landslide reached runout velocities of $200 \mathrm{~m} \mathrm{~s}^{-1}$. Secondly, the deposit's thickness right after impact is reported as $1040 \mathrm{~m}$, which is likely an overestimation (Fig. S1). The model does not differentiate between the rockfall on the ground and what we call the dust cloud. It remains unclear whether the fine particles reached such an elevation, but it appears a possible option. Finally, we ran only a small number of models with different combinations of the input parameters (Table 3). Nevertheless, within these model runs, we managed to implement several parameter combinations, and at least one resulted in a realistic landslide runout. Thus, the feasibility of the proposed processes was tested successfully, and we achieved the primary goal of runout modelling.

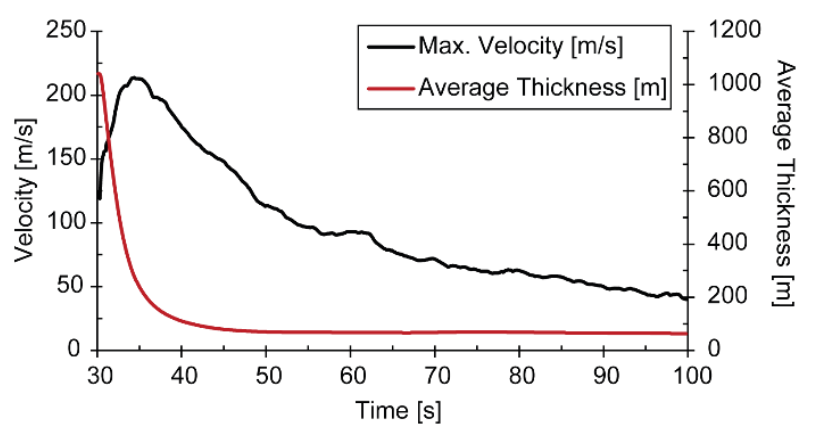

Figure S1: Dan3D-Flex output from the best-fit runout model from the moment of valley floor impact. 
The initial landslide filled a sediment-limited valley, with a stream that incised the bedrock, with large amounts of unconsolidated sediment. Thus, to guarantee a representative flow surface for the landslide runout modelling, it was necessary to approximate these conditions by "removing" the Holocene deposits and reconstruct the previous mountain face topography. ArcMap 10.2 was used for calculations.

For the Holocene deposits in the valley, we assumed a constant thickness throughout the valley, with their upper depositional surfaces minimally modified by post-depositional processes (e.g. subsequent erosion). Twenty-six topographic profiles, up to 1,200 $\mathrm{m}$ in length, were constructed across the valley's width (Fig. S2). The profiles were assigned elevation values from a $5 \mathrm{~m}$ DEM that were then exported to an attribute table and an imaging program. Using our detailed field observations and reports by Booth (2010), we visually marked the landslide locations and alluvial infill deposits on these profiles. Subsequently, the deposit thicknesses were subtracted from the modern topography, resulting in an estimate of the valley's pre-landslide bedrock topography (DEMpre).

For the reconstruction of the mountain face, we utilised a method provided by ArcGIS, minimum bounding volume with a concave hull, which requires a point cloud on the target area, whose attributes are used to calculate and visualise the volume of the missing material (Fig. S3; Table 2). The maximum extent likely overestimates the rock fall area and it was not used in the subsequent runout modelling.
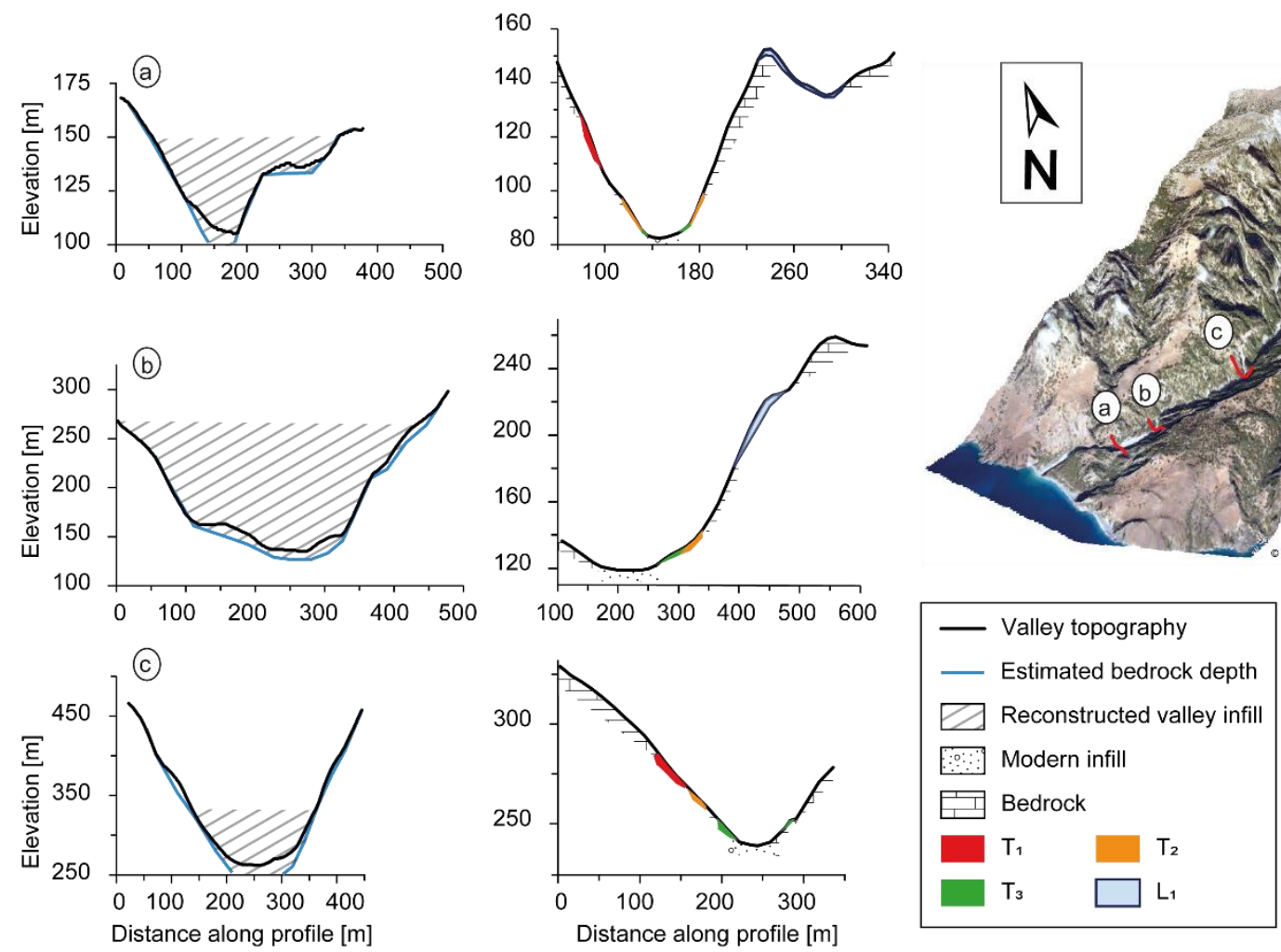

Figure S2: Left panel: Exemplary valley profiles of modern topography (black curve), whose location is highlighted in the 3D imagery (red) produced using ArcScene 10.6.1 (ESRI, 2011). The blue curve is assumed bedrock depth as calculated from subtracting the thickness of each Holocene infill deposit from the modern topography (DEMpre). The striped shading represents the assumed landslide infill based on field mapping and volume calculations. The process was repeated for 26 profiles across the river, and the results were implemented to produce DEMpre. Right panel: Mapping of the Holocene deposits at the location of each profile. The thicknesses are not representative. 


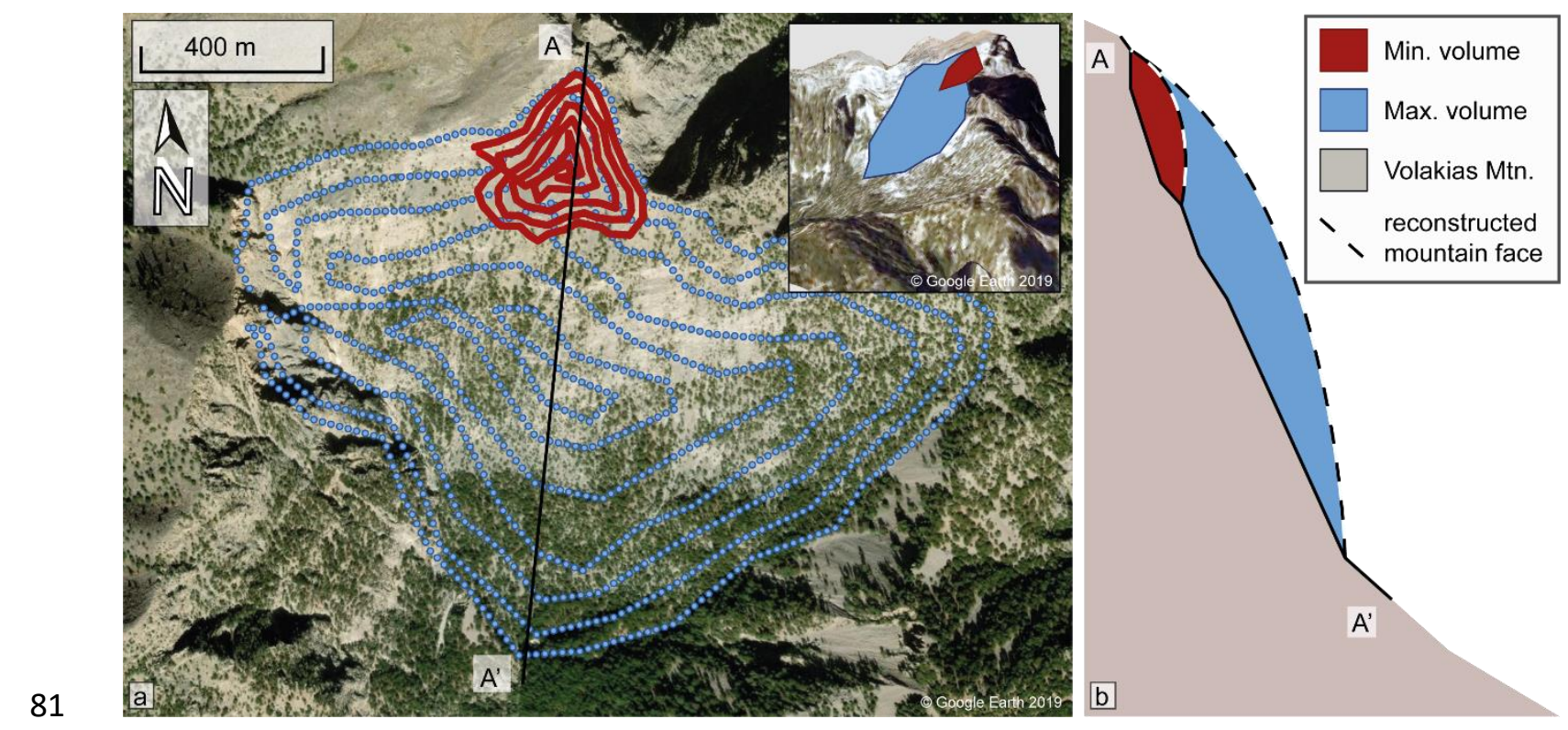

82 Figure S3: Visualisation of the maximum and minimum extents of a possible rock fall, and the reconstruction of their volumes $\left(3.82 \times 10^{9} \mathrm{~m}^{3}\right.$ and $2.8 \times 10^{5} \mathrm{~m}^{3}$ ). (a) The calculation is based on a set of georeferenced points on the rockfall source area, which were transferred to a multipatch feature that visualises the volume and area as defined by the input data. The inset shows the break-off area as calculated from the georeferenced points in (a), (b) A side view sketch of the resulting multipatch feature. A minimum bounding volume method with a concave hull, was utilized in ArcGIS for the calculations. 
90 Table S1: Detailed report of bulk sediment radiocarbon measurements. All measurements were conducted at the Laboratory 91 of Ion Beam Physics, ETH Zürich.

\begin{tabular}{llllllllll}
\hline $\begin{array}{l}\text { ETH } \\
\text { number }\end{array}$ & Label & Description & $\mathbf{C}(\boldsymbol{\mu g})$ & $\mathbf{F m}$ & $\begin{array}{l}\text { Error } \\
\text { absolute }\end{array}$ & $\begin{array}{l}\text { Fm } \\
\text { corrected }\end{array}$ & Error & $\begin{array}{l}\mathbf{1 4}^{\mathbf{1 4}} \mathbf{C} \text { ages } \\
(\mathbf{y r s}, \mathbf{1} \text { })\end{array}$ & $\begin{array}{l}\text { Error } \\
(\mathbf{y r s})\end{array}$ \\
\hline 94494.1 .1 & 4 & Tributary deposit 1 & 37 & 0.5729 & 0.00690 & 0.55 & 0.04 & 4820 & 556 \\
87102.1 .1 & 4 & Tributary deposit 1 & 41 & 0.7111 & 0.00694 & 0.71 & 0.03 & 2696 & 369 \\
94495.1 .1 & 5 & Tributary deposit 2 & 52 & 0.5660 & 0.00690 & 0.55 & 0.03 & 4820 & 379 \\
87100.1 .1 & 5 & Tributary deposit 2 & 30 & 0.6630 & 0.00657 & 0.66 & 0.05 & 3389 & 587 \\
94493.1 .1 & 6 & Lower fan & 27 & 0.5832 & 0.00680 & 0.55 & 0.05 & 4793 & 826 \\
94491.1 .1 & 7 & Upper fan 1 & 29 & 0.5309 & 0.00650 & 0.49 & 0.05 & 5788 & 874 \\
87099.1 .1 & 7 & Upper fan 1 & 24 & 0.6128 & 0.00714 & 0.59 & 0.06 & 4304 & 903 \\
87103.1 .1 & 8 & Upper fan 2 & 20 & 0.5792 & 0.00602 & 0.53 & 0.08 & 5131 & 1342 \\
94496.1 .1 & 9 & Landslide deposit & 42 & 0.7280 & 0.00740 & 0.73 & 0.03 & 2476 & 351 \\
87098.1 .1 & 9 & Landslide deposit & 23 & 0.6709 & 0.00737 & 0.66 & 0.07 & 3294 & 831 \\
\hline
\end{tabular}




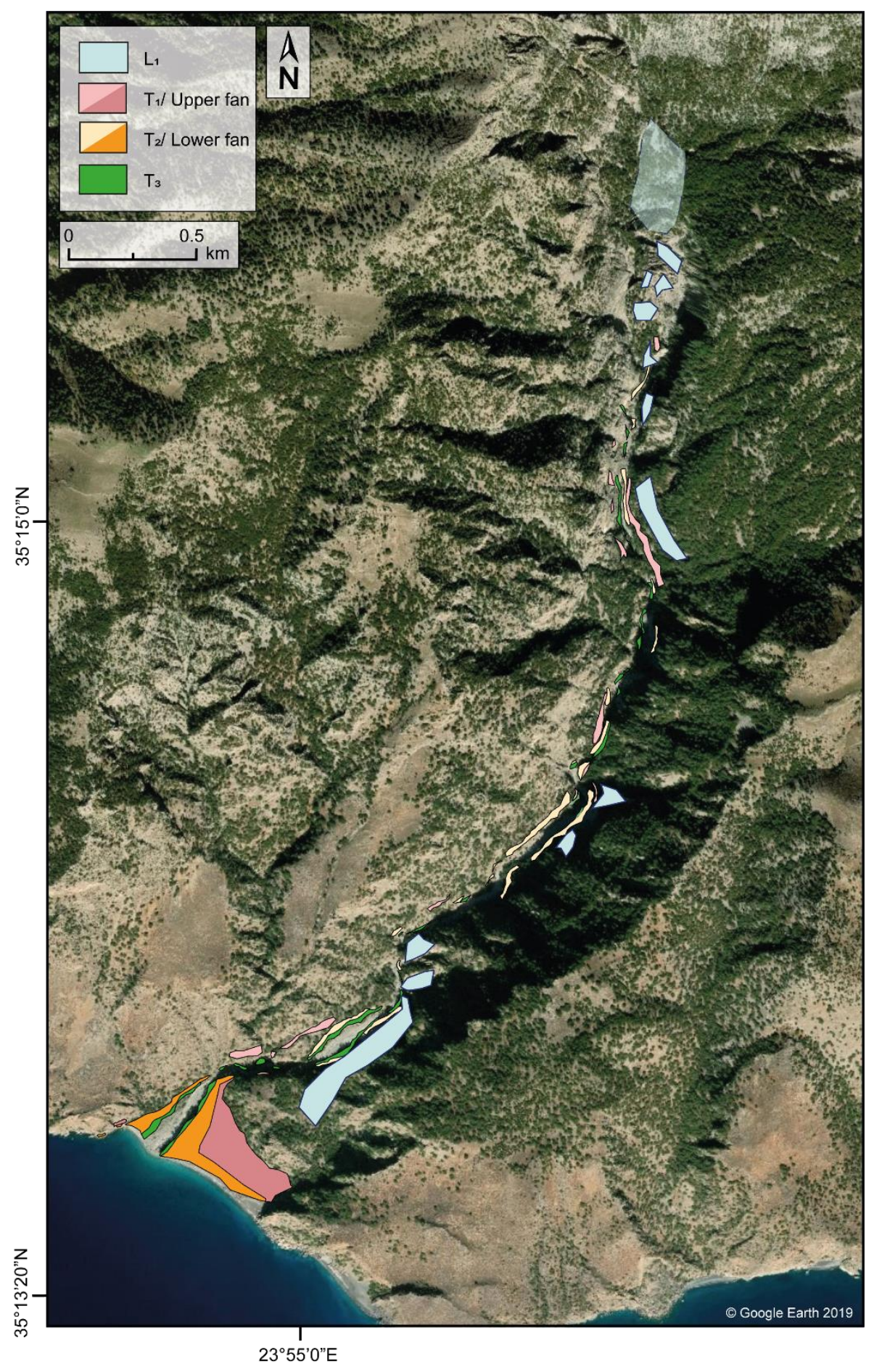

95 Figure S4: Full-valley mapping of sedimentary deposits and landslide deposits. All deposits are distributed along the valley's 96 entire length, suggesting a shared place of origin in the headwaters. For more mapping details of the terrace and fan deposits, 97 see Booth (2010). 
100 To support statements regarding differences in the degree of soil development and maturity between Pleistocene

101 fan deposits in southern Crete and the Holocene fans studies in the Klados catchment, we provide photos for 102 comparison in Figure S5.
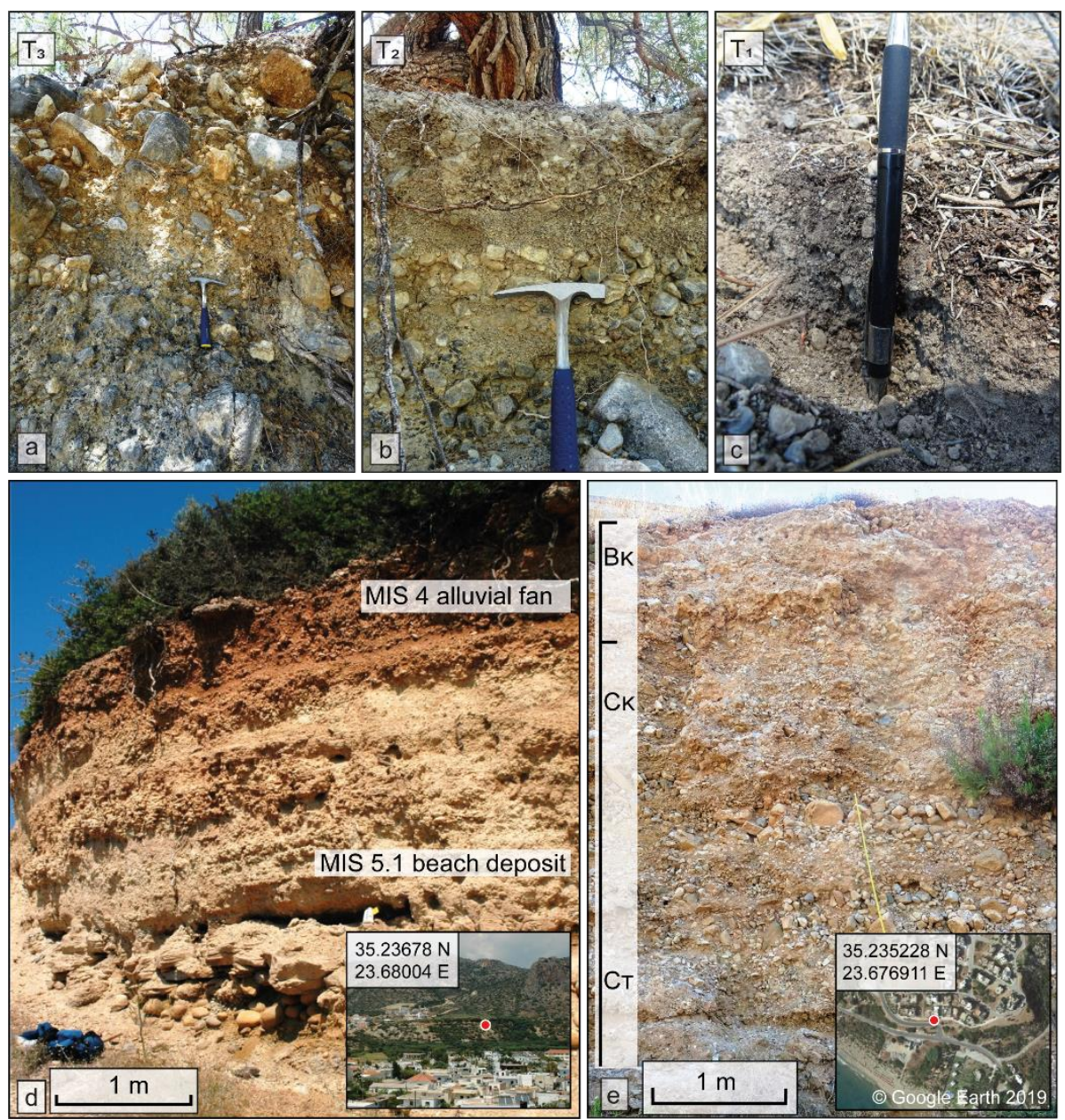

Figure S5: Minor soil development on $\mathrm{T}_{3}(\mathrm{a}), \mathrm{T}_{2}(\mathrm{~b})$, and $\mathrm{T}_{1}$ (c) results in low soil maturity. Typically, a surface horizon of non-degraded organic matter such as pine needles overlies the original alluvial deposits. Soil formation may be accelerated in close proximity to larger plants such as pine trees, but we find no sign of wide-spread pedogenesis. (d) Outcrop "Alta Paleohora" (20 km W of Klados, exact location noted) showing dated MIS 4 alluvial fan material over MIS 5.1 beach deposits (Pope et al., 2008). (e) Outcrop in Paleohora (exact location noted), carbonaceous terrace of MIS 2. B = top soil, C = source rock, $\mathrm{K}=$ secondary carbonates, $\mathrm{T}$ = clay-enriched (IUSS Working Group WRB, 2015). 
111

112

113

114

115

116

117

118

119

120

121

122

123

124

125

126

127

128

129

130

131

132

133

134

135

136

137

138

139

140

141

142

143

144

145

146

147

\section{Introduction}

Sharp geomorphic features, such as earthquake fault scarps and river terrace risers, smooth over time due to active hillslope processes such as rain splash, creep, and tree throw (i.e., Carson and Kirkby, 1972; Selby and Hodder, 1993). This process can be approximated by simple diffusion models, which, when calibrated, have been used to infer the timing of an earthquake or abandonment of a terrace (i.e., Culling, 1960; Fernandes and Dietrich, 1997). Here, we use a linear diffusion model, the current and reconstructed initial morphology of the paleo-sea cliff associated with the upper fan unit in Klados, and the inferred timing of sea cliff abandonment from this study (5$7 \mathrm{kyr}$ ) and from Mouslopoulou et al. (2017) (35-45 kyr) to calibrate the diffusion coefficient. We then compare these results to a global compilation of diffusion coefficients to assess which result is more likely given the climate and substrate.

\section{Methods}

We construct a structure from a motion (SfM) digital surface model (DSM) for the Klados coastal fan sequence from images collected from a DJI Phantom 3 drone using the AgiSoft photogrammetry software. The SfM point cloud was converted to a DSM with a horizontal resolution of $15 \mathrm{~cm}$ (Fig. S5a, b). From the DSM, we extracted two $10 \mathrm{~m}$ wide swath profiles from the modern shoreline and onto the upper fan surface in transection with minimal vegetation (Fig. S5a, b). To minimize the impact of vegetation, we generate profiles using the minimum values in the swath profile (grey lines in Fig. S5c, d). These profiles were used in the diffusion modelling.

We reconstructed the initial paleo-sea cliff morphology by performing a linear regression on the lower fan tread surface with little observed disturbance and the upper portion of the sea cliff and projected each regression upslope and downslope, respectively. The intersection of these two regressions is assumed to be the location where the paleo-sea cliff and lower terrace surface met before hillslope processes smoothed the cliff face. The regressions and the intersection point were used to reconstruct the initial morphology of the paleo-seacliff for each profile (blue line in Fig. S5c, d).

To model diffusion, we solved the linear diffusion equation using explicit finite difference techniques. The linear diffusion equation states:

$\frac{d z}{d t}=D \frac{d^{2} z}{d x^{2}}$

where $z$ is elevation, $t$ is time, $x$ is distance, and $D$ is the diffusion coefficient. To find the best-fit $D$ for each model run, we conducted a brute-force search, running the model for a prescribed time interval ( $5-7 \mathrm{kyr}$ for the Holocene hypothesis and $35-45 \mathrm{ky}$ for the Pleistocene hypothesis) and compared the fit of the final model to the observed profile with a goodness-of-fit metric. The diffusion coefficient that maximized the goodness of fit was deemed the best fit solution for a given model run.

\section{Results}

The best-fit results for a given model run time all fit the observed profile equally well, and for this reason, we only show one best-fitting profile (green line in Fig. S5c, d). There are some mismatches between the observed and modelled profiles that are likely explained by processes not included in the simply linear diffusion model, but despite these discrepancies, the results provide a reasonable approximation of the modern paleo-seacliff morphology. The diffusion coefficients for our preferred Holocene ( $5-7 \mathrm{kyr})$ abandonment timing of the seacliff 
148 range between $\sim 35$ and $100 \mathrm{~cm} 2 / \mathrm{yr}$ and those from Pleistocene ( 35 - $45 \mathrm{kyr}$ ) abandonment timing range between

$149 \sim 6$ and $14 \mathrm{~cm} 2 / \mathrm{yr}$ (Fig. S5e, f).

150 Discussion

151 To assess if the best-fit results are reasonable, we compare them to a global compilation of diffusion coefficients

152 (Fig. S5e, f; Richardson et al. (2019)). The data are plotted with respect to mean annual precipitation (MAP), as

153 a proxy for climate, and the global data also classified in terms of substrate material (Fig. S5e) and overlying

154 vegetation (Fig. S5f). Comparison of our results with the global compilation shows that the diffusion coefficients

155 for Klados for both the Holocene and Pleistocene models are within the range of published results (Fig. S5e, f).

156 However, the Holocene diffusion coefficient lies within the highest concentration of data points for the given

157 MAP, and the Pleistocene value is low. Furthermore, considering the material (unconsolidated sediment) and the

158 overlying vegetation scrubland to lightly forested) within the context of the global compilation, we consider the

159 Holocene model more reasonable than the Pleistocene model. While not conclusive, these findings lend support

160 to our preferred Holocene emplacement of the Klados alluvial fill units. 

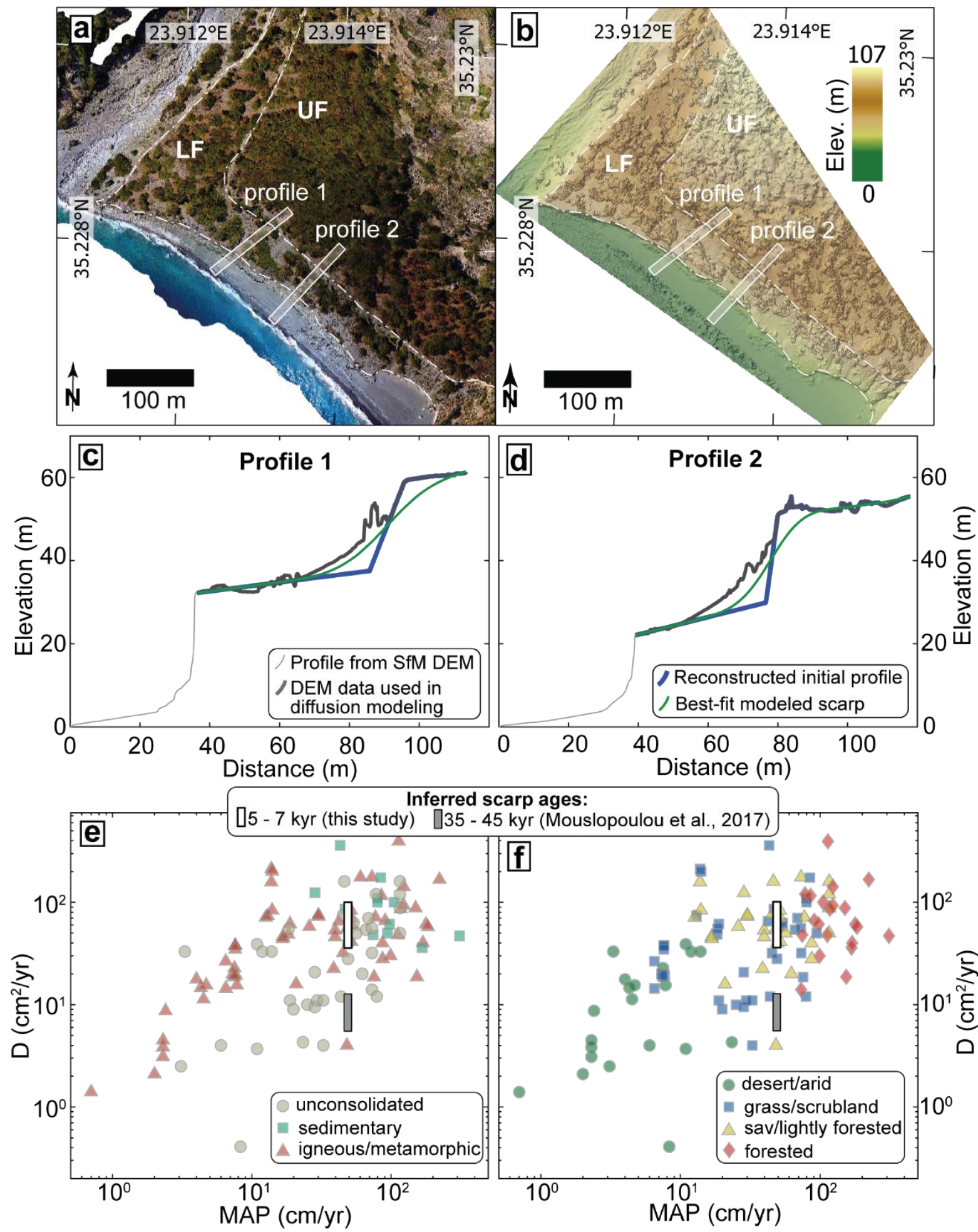

Figure S6: Structure from motion (SfM) photomosaic, digital surface model (DSM), and diffusion modelling results. (a) and (b) show the SfM photomosaic and DSM result, respectively, along with the location of the two swath profiles (LF - lower fan, UF - upper fan). (c) and (d) are the minimum elevations of the swath profile (grey lines), which are assumed to approximate the vegetation-free fan morphology. Also shown on both plots is the initial (blue line) and the final modelled (green line) topographic profiles for the upper fan. The bold grey line shows the data used in the diffusion modelling. (e) and (f) show the best fit diffusion coefficient, $D$, results for the Holocene and Pleistocene age models as the white and great vertical rectangles, respectively, plotted against mean annual precipitation (MAP). Also shown is the global compilation of diffusion coefficients from Richardson et al. (2019) classified based on substrate (e) and overlying vegetation (f). 
Aaron, J. and Hungr, O.: Dynamic analysis of an extraordinarily mobile rock avalanche in the Northwest Territories, Canada, Can. Geotech. J., 53(6), 899-908, doi:10.1139/cgj-2015-0371, 2016a.

Aaron, J. and Hungr, O.: Dynamic simulation of the motion of partially-coherent landslides, Eng. Geol., 205, 111, doi:10.1016/j.enggeo.2016.02.006, 2016 b.

Aaron, J., McDougall, S., Moore, J. R., Coe, J. A. and Hungr, O.: The role of initial coherence and path materials in the dynamics of three rock avalanche case histories, Geoenvironmental Disasters, 4(1), 5, doi:10.1186/s40677-017-0070-4, 2017.

Allen, S. K., Schneider, D. and Owens, I. F.: First approaches towards modelling glacial hazards in the Mount Cook region of New Zealand's Southern Alps, Nat. Hazards Earth Syst. Sci., 9(2), 481-499, doi:10.5194/nhess-9-481-2009, 2009.

Booth, J.: The response of Mediterranean steepland coastal catchments to base level and climate change, southwestern Crete, Aberystwyth University., 2010.

Carson, M. A. and Kirkby, M. J.: Hillslope materials and processes, Cambridge University Press., 1972.

Culling, W. E. H.: Analytical Theory of Erosion, J. Geol., 68(3), 336-344, doi:10.1086/626663, 1960.

Davies, T. R. and McSaveney, M. J.: The role of rock fragmentation in the motion of large landslides, Eng. Geol., 109(1-2), 67-79, doi:10.1016/j.enggeo.2008.11.004, 2009.

ESRI: National Geographic World Map, digital topographic basemap of the world., Natl. Geogr. Esri, DeLorme, NAVTEQ, UNEP-WCMC, USGS, NASA, ESA, METI, NRCAN, GEBCO, NOAA, IPC [online] Available from: $\quad$ https://www.arcgis.com/home/item.html?id=b9b1b422198944fbbd5250b3241691b6\#overview (Accessed 21 September 2017), 2011.

Fernandes, N. F. and Dietrich, W. E.: Hillslope evolution by diffusive processes: The timescale for equilibrium adjustments, Water Resour. Res., 33(6), 1307-1318, doi:10.1029/97WR00534, 1997.

Grämiger, L. M., Moore, J. R., Vockenhuber, C., Aaron, J., Hajdas, I. and Ivy-Ochs, S.: Two early Holocene rock avalanches in the Bernese Alps (Rinderhorn, Switzerland), Geomorphology, 268, 207-221, doi:10.1016/j.geomorph.2016.06.008, 2016.

Hungr, O.: A model for the runout analysis of rapid flow slides, debris flows, and avalanches, Can. Geotech. J., 32(4), 610-623, doi:10.1139/t95-063, 1995.

Hungr, O. and Evans, S. G.: Rock avalanche runout prediction using a dynamic model, Proc. 7th Int. Symp. Landslides, Trondheim, Norw., 17, 21 [online] Available from: http://www.claraw.com/DANWReference2.pdf, 1996.

IUSS Working Group WRB: World Reference Base for Soil Resources 2014, update 2015: International soil classification system for naming soils and creating legends for soil maps., Rome., 2015.

McDougall, S. and Hungr, O.: A model for the analysis of rapid landslide motion across three-dimensional terrain, Can. Geotech. J., 41, 1084--1097, doi:10.1139/T04-052, 2004.

McSaveney, M. J. and Davies, T. R.: Inferences from the morphology and internal structure of rockslides and rock avalanches rapid rock mass flow with dynamic fragmentation, in Landslides from Massive Rock Slope Failure, edited by S. G. Evans, G. S. Mugnozza, A. Strom, and R. L. Hermanns, Springer, Dordrecht., 2006.

Mouslopoulou, V., Begg, J., Fülling, A., Moraetis, D. and Partsinevelos, P.: Distinct phases of eustatic and tectonic forcing for late Quaternary landscape evolution in southwest Crete , Greece, Earth Surf. Dyn., 5, 511-527, 2017.

Nagelisen, J., Moore, J. R., Vockenhuber, C. and Ivy-Ochs, S.: Post-glacial rock avalanches in the Obersee Valley, Glarner Alps, Switzerland, Geomorphology, 238, 94-111, doi:10.1016/j.geomorph.2015.02.031, 2015.

Preuth, T., Bartelt, P., Korup, O. and McArdell, B. W.: A random kinetic energy model for rock avalanches: Eight case studies, J. Geophys. Res. Earth Surf., 115(3), F03036, doi:10.1029/2009JF001640, 2010.

Richardson, P. W., Perron, J. T. and Schurr, N. D.: Influences of climate and life on hillslope sediment transport, Geology, 47(5), 423-426, doi:10.1130/G45305.1, 2019.

Scheidegger, A. E.: On the prediction of the reach and velocity of catastrophic landslides, Rock Mech. Felsmechanik Mécanique des Roches, 5(4), 231-236, doi:10.1007/BF01301796, 1973. 
Selby, M. J. and Hodder, A. P. W.: Hillslope materials and processes, Oxford University Press., 1993.

Sosio, R., Crosta, G. B. and Hungr, O.: Complete dynamic modeling calibration for the Thurwieser rock avalanche (Italian Central Alps), Eng. Geol., 100(1-2), 11-26, doi:10.1016/j.enggeo.2008.02.012, 2008.

USGS: Catastrophic Landslides of the 20th Century - Worldwide, USGS - Landslide Hazards [online] Available from: https://www.usgs.gov/natural-hazards/landslide-hazards/science/catastrophic-landslides-20th-centuryworldwide?qt-science_center_objects=0\#qt-science_center_objects (Accessed 20 July 2018), 2016.

Xing, A. G., Xu, Q. and Gan, J. J.: On characteristics and dynamic analysis of the Niumian valley rock avalanche triggered by the 2008 Wenchuan earthquake, Sichuan, China, Environ. Earth Sci., 73(7), 3387-3401, doi:10.1007/s12665-014-3626-6, 2015. 